\title{
ASO Visual Abstract: Assessing Interobserver Variability of Cosmetic Outcome Assessment in Breast Cancer Patients Undergoing Breast Conservation Surgery
}

\author{
Anees B. Chagpar, MD, MSc, MPH, MA, MBA, FRCS(C), FACS, Elizabeth Berger, MD, \\ Michael Alperovich, MD, Gregory Zanieski, MD, Tomer Avraham, MD, and Donald R. Lannin, MD \\ Department of Surgery, Yale University School of Medicine, New Haven, CT
}

While patients' reported self-assessments of cosmetic outcome after breast-conserving surgery are considered subjective, there is a paucity of data to assess the interobserver variability between surgeons, using gradation scales of cosmesis, and the correlation of these with patients' perceptions (https://doi.org/10.1245/s10434-021-10442-y).

\section{Assessing Interobserver Variability of Cosmetic Outcome Assessment in Breast Cancer Patients Undergoing Breast Conservation Surgery}

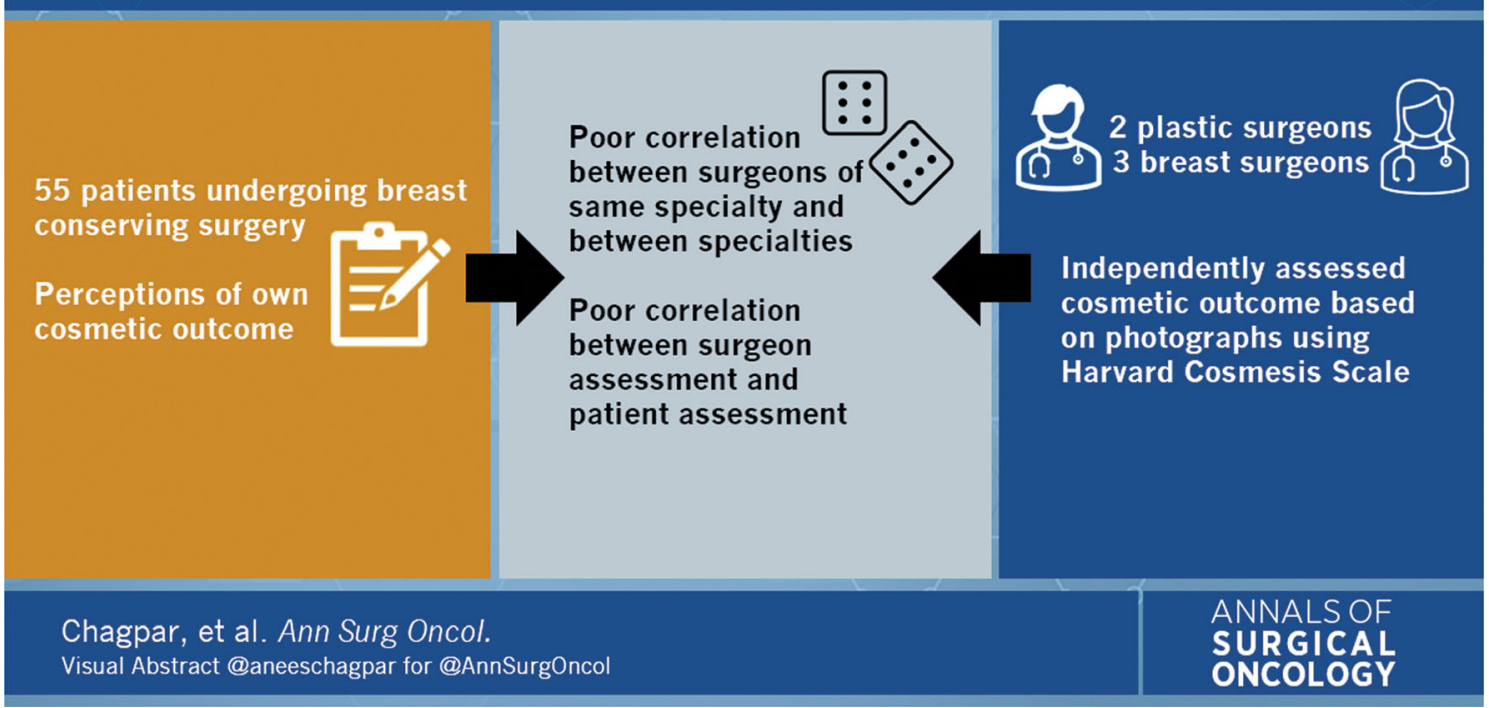

Presented at the American Society of Breast Surgeons Annual Meeting, 29 April-2 May 2021.

(C) Society of Surgical Oncology 2021

Published Online: 18 August 2021

A. B. Chagpar, MD, MSc, MPH, MA, MBA, FRCS(C), FACS e-mail: anees.chagpar@yale.edu
DISCLOSURE Anees B. Chagpar, Elizabeth Berger, Michael Alperovich, Gregory Zanieski, Tomer Avraham, and Donald R. Lannin have no commercial conflicts of interest pertinent to this work.

Publisher's Note Springer Nature remains neutral with regard to jurisdictional claims in published maps and institutional affiliations. 